\title{
Multi-institutional prospective feasibility study to explore tolerability and efficacy of oral nutritional supplements for patients with gastric cancer undergoing gastrectomy (CCOG1301)
}

\author{
Daisuke Kobayashi $^{1} \cdot$ Kiyoshi Ishigure $^{2} \cdot$ Yoshinari Mochizuki $^{3} \cdot$ Hiroshi Nakayama $^{4} \cdot$ \\ Mitsuru Sakai $^{5} \cdot$ Seiji Ito $^{6} \cdot$ Hiroshi Kojima $^{7} \cdot$ Masaki Kajikawa $^{8}$. \\ Masahiko Ando ${ }^{9} \cdot$ Yasuhiro Kodera $^{1}$
}

Received: 20 July 2016/Accepted: 8 November 2016/Published online: 24 November 2016

(c) The International Gastric Cancer Association and The Japanese Gastric Cancer Association 2016

\begin{abstract}
Background Postoperative malnutrition after gastrectomy is deemed inevitable, which could have prejudicial influence on survival for gastric cancer patients. A prospective feasibility study was conducted to evaluate the efficacy of postoperative oral nutritional supplements.

Methods Stage I-III gastric cancer patients who underwent distal or total gastrectomy received oral administration of Racol ${ }^{\circledR}$ NF (Otsuka Pharmaceutical Factory, Japan), a liquid enteral nutritional formula, as a supplement to regular meals. Racol ${ }^{\circledR} \mathrm{NF}$ administration at a recommended dosage of $400 \mathrm{kcal} / 400 \mathrm{ml}$ per day was started within 7 days postoperatively and was continued for 3 months
\end{abstract}

Daisuke Kobayashi

kobadai@med.nagoya-u.ac.jp

1 Department of Gastroenterological Surgery, Nagoya University Graduate School of Medicine, 65 Tsurumai-cho, Showa-ku, Nagoya 466-8550, Japan

2 Department of Surgery, Konan Kosei Hospital, Konan, Japan

3 Department of Surgery, Komaki City Hospital, Komaki, Japan

4 Department of Surgery, National Hospital Organization Nagoya Medical Center, Nagoya, Japan

5 Department of Surgery, Ichinomiya Municipal Hospital, Ichinomiya, Japan

6 Department of Gastroenterological Surgery, Aichi Cancer Center, Nagoya, Japan

7 Gastroenterological Surgery, Aichi Cancer Center Aichi Hospital, Okazaki, Japan

8 Department of Surgery, Gifu Prefectural Tajimi Hospital, Tajimi, Japan

9 Center for Advanced Medicine and Clinical Research, Nagoya University Hospital, Nagoya, Japan postoperatively. The primary end point was ratio of the weight loss at 3 months postoperatively to the preoperative body weight (body weight loss ratio). Secondary end points were the adherence to Racol ${ }^{\circledR}$ NF therapy and changes in body composition.

Results One hundred eighteen patients were registered before surgery, 82 of whom were eligible for efficacy analyses. The average rate of body weight loss after 3 months postoperatively was $8.3 \%$. The mean daily intake of Racol ${ }^{\circledR} \mathrm{NF}$ was $211 \mathrm{ml}$. There was a significant correlation between adherence to Racol ${ }^{\circledR} \mathrm{NF}$ therapy and body weight loss ratio $(P<0.001)$. Adherence to $\operatorname{Racol}^{\circledR} \mathrm{NF}$ therapy was the only factor that correlated with the body weight loss ratio among all clinical characteristics by the multiple linear regression analysis $(P=0.007)$.

Conclusions Oral nutritional supplementation with Racol ${ }^{\circledR}$ NF led to a significant reduction in body weight loss for gastrectomized patients who tolerated more than $200 \mathrm{ml}$ of the nutrient per day compared with those who could not tolerate this amount.

Keywords Gastric cancer · Gastrectomy · Malnutrition · Oral nutritional supplements

\section{Introduction}

Gastric cancer is the third commonest cause of cancer death worldwide, and claimed the lives of 723,000 people in 2012 [1]. Standard gastrectomy continues to play a major role in the treatment of resectable gastric cancer, and comprises resection of the distal part of more than two thirds of the whole stomach along with concomitant lymphadenectomy [2]. Postoperative malnutrition due to, among other things, the loss of reservoir function in the 
upper gastrointestinal tract is deemed inevitable [3], and patients who underwent open distal gastrectomy demonstrated body weight loss (BWL) of $13 \%$ in the 6 months postoperatively, whereas those who underwent total gastrectomy lost $17 \%$ of body weight [4].

Malnutrition after gastrectomy has long been considered to be associated with postoperative complications and morbidity $[5,6]$, which in itself could have prejudicial influence on survival for gastric cancer patients after curative surgery [7, 8]. In addition, adjuvant chemotherapy is a standard component of treatment for advanced gastric cancer in Japan [9], and excess BWL after gastrectomy has been reported to compromise the duration of $\mathrm{S}-1$ monotherapy [10]. In the Medical Research Council Adjuvant Gastric Cancer Infusional Chemotherapy (MAGIC) trial, which examined the benefit of perioperative chemotherapy [11], a clear difference in the adherence to the identical chemotherapeutic regimen was observed between the preoperative phase and the postoperative phase. These findings suggest that there should be room for improvement in the treatment outcome of gastric cancer patients through the provision of some form of nutritional support postoperatively.

The European Society for Clinical Nutrition and Metabolism (ESPEN) introduced the concept of oral nutritional supplements (ONS) to the ESPEN guidelines on enteral nutrition [12]. Oral nutritional supplementation is defined as supplementary oral intake of dietary food for special medical purposes in addition to the normal food. In the ESPEN guidelines on enteral nutrition for surgery, patients who do not obtain their energy needs from normal food are encouraged to take ONS during the preoperative period [13]. However, there is paucity of evidence for a benefit of prolonged postoperative nutritional intervention that continues after discharge from the hospital among those who have undergone gastrectomy.

As an attempt to clarify this issue, the Chubu Clinical Oncology Group (CCOG) conducted a prospective multicenter trial (CCOG1301) to explore the feasibility and effectiveness of ONS among patients with gastric cancer with the BWL ratio as the primary end point. Supplementation with Racol ${ }^{\circledR}$ NF (Otsuka Pharmaceutical Factory, Japan), a liquid enteral nutritional formula, began after surgery and was continued for 3 months.

\section{Patients and methods}

\section{Patient eligibility}

Eligibility criteria included (1) patients aged 20 years or older, (2) preoperative diagnosis of stage I, II, or III gastric cancer, (3) patients in whom distal or total gastrectomy was planned, (4) Eastern Cooperative Oncology Group performance status of 0-2, (5) body mass index less than $25 \mathrm{~kg} /$ $\mathrm{m}^{2}$, (6) ability to take an enteral feeding product in conjunction with oral ingestion, and (7) written informed consent from the patient after the nature of the study had been explained. Exclusion criteria included synchronous or metachronous second primary malignancy, active infections, necessity of diet or fluid restriction along with other treatments for the concurrent disease, severe or uncontrolled concomitant illness accompanied by weight loss, patients who underwent neoadjuvant chemotherapy, contraindication for taking Racol ${ }^{\circledR} \mathrm{NF}$, patients with a pacemaker or severe cardiac arrhythmia, and pregnant or lactating women.

\section{Study design}

CCOG1301 is a prospective, multicenter clinical trial conducted at 17 institutions in the Chubu district of Japan. The study protocol was approved by the independent ethics committee or institutional review board of each participating institution. This trial was registered with the University Hospital Medical Information Network (UMIN000011410).

After patients had been checked for eligibility, the patients were registered before undergoing surgery. Oral nutritional supplementation with $\mathrm{Racol}^{\circledR} \mathrm{NF}$ as a supplement to regular meals was to be started within 7 days postoperatively and continued for 3 months postoperatively until the 90th postoperative day.

The primary end point was BWL ratio at 3 months postoperatively. The sample size was kept small at 100 patients, which is a realistic number for enrollment by the participating institutions within the given time that would nevertheless produce preliminary data to generate hypotheses for a future randomized trial to formally address the benefits of ONS. The secondary end points were adherence to $\mathrm{Racol}^{\circledR} \mathrm{NF}$ therapy, changes in body composition at 3 months postoperatively and changes in serum biochemistry at 3 months postoperatively.

\section{Treatment}

Patients received oral administration of $\mathrm{Racol}^{\circledR} \mathrm{NF}$ as a supplement to regular meals. Administration of Racol ${ }^{\circledR} \mathrm{NF}$ at a recommended dosage of $400 \mathrm{kcal} / 400 \mathrm{ml}$ per day was to be started within 7 days postoperatively and continued for 3 months. The time at which $\mathrm{Racol}^{\circledR} \mathrm{NF}$ was taken during the day and the amount taken were left to the discretion of the patients. Racol ${ }^{\circledR} \mathrm{NF}$ intake after the first 3 months postoperatively was not stipulated. Dose reduction or interruption of Racol ${ }^{\circledR} \mathrm{NF}$ therapy was to be considered in the event of the adverse effects related to 
Racol ${ }^{\circledR}$ NF such as diarrhea, abdominal pain, and vomiting. Patients with a diagnosis of stage II or stage III gastric cancer pathologically except those with pT1pN2 or pT3pN0 status were to be given evidence-based adjuvant chemotherapy with S-1 for 12 months according to the Japanese treatment guidelines for gastric cancer [2]. Nutritional medication other than $\operatorname{Racol}{ }^{\circledR} \mathrm{NF}$ was not allowed.

\section{Assessments}

Patient characteristics including vital signs, Eastern Cooperative Oncology Group performance status, and clinical backgrounds were assessed and recorded within 14 days before surgery after written informed consent had been obtained from the patients. Measurements of body composition and serum biochemistry were performed at the baseline (preoperatively) and at 1,2, and 3 months after the gastrectomy with the allowance for a deviation in the measurement day of \pm 7 days. Body weight, muscle mass, and fat mass were measured by segmental multifrequency bioelectrical impedance analysis performed with a DC-320 body composition analyzer (Tanita, Tokyo, Japan). The height and the waist circumference of each patient were measured before each evaluation of body composition as parameters that were mandatory for calculation of body composition data.

Data on treatment adherence were collected through questionnaires completed by the patients. A dedicated cup with a scale showing the 50-ml line was delivered to each patient for measurement of the daily Racol ${ }^{\circledR} \mathrm{NF}$ intake. The daily oral food intake, which was rated as $0 \%, 25 \%$, $50 \%, 75 \%$, or $100 \%$ in relation to the preoperative level of oral ingestion, was simultaneously collected through the questionnaire.

\section{Statistics}

The full analysis set was the major analysis object for the purpose of effective assessment, and was defined as those patients who took $\mathrm{Racol}^{\circledR} \mathrm{NF}$ at least once during the defined period. The Wilcoxon signed-rank test was used to assess body weight change before and 3 months after surgery. Correlation between adherence to $\operatorname{Racol}^{\circledR} \mathrm{NF}$ therapy and BWL was analyzed. Patients were divided into two cohorts according to their adherence to $\operatorname{Racol}^{\circledR} \mathrm{NF}$ therapy or the oral food intake. The chi-square test, Fisher's exact test, and the Mann-Whitney $U$ test were used to assess differences between the two groups. The linear mixed model was used to compare BWL throughout the defined postoperative period between the two groups. Multiple linear regression analysis was conducted to explore the factors related to BWL. Differences were considered significant at $P<0.05$. All statistical analyses were performed with IBM SPSS Statistics version 23.0 (IBM, Armonk, NY, USA).

\section{Results}

\section{Patients}

From October 2013 to September 2014, 118 patients were enrolled before surgery from 12 institutions, and data for 82 patients were available for efficacy analyses. The 36 patients deemed ineligible consisted of 13 patients whose adherence records could not be retrieved at the end of the treatment period, 11 patients who were found to have stage IV disease pathologically, 8 patients who failed to start taking $\operatorname{Racol}^{\circledR} \mathrm{NF}$ within 7 days postoperatively, and 4 patients with other reasons (Fig. 1). The clinicopathological features of the patients are given in Table 1.

\section{Treatment adherence}

The total intake of $\mathrm{Racol}^{\circledR} \mathrm{NF}$ during the 3 months postoperatively was divided by the recommended amount of $\mathrm{Racol}^{\circledR} \mathrm{NF}(400 \mathrm{ml} \times 83$ days $=33,200 \mathrm{ml})$ to calculate the relative dose intensity of Racol ${ }^{\circledR} \mathrm{NF}$ in each patient. The average dose intensity of $\mathrm{Racol}^{\circledR} \mathrm{NF}$ was $52.7 \%$ (95\% CI $46.5-58.8 \%$ ), which was equivalent to $211 \mathrm{ml}(95 \% \mathrm{CI} 186-236 \mathrm{ml})$ as the daily $\mathrm{Racol}^{\circledR} \mathrm{NF}$ intake (Fig. 2). No severe adverse effects that required medical attention or life-threatening events related to $\mathrm{Racol}^{\circledR} \mathrm{NF}$ were observed. There were some gastrointestinal disorders, including diarrhea in two patients (2.4\%), appetite loss in one patient (1.2\%), and nausea in one patient $(1.2 \%)$, that were reversible after cessation of the drug.

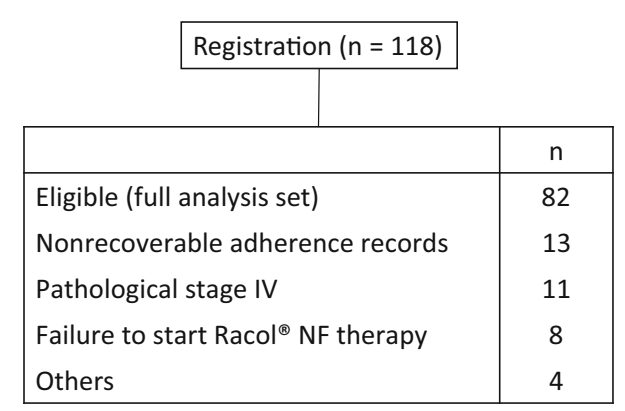

Fig. 1 CONSORT diagram 
Table 1 Characteristics of patients $(N=82)$

\begin{tabular}{|c|c|}
\hline Variable & Value \\
\hline \multicolumn{2}{|l|}{ Sex } \\
\hline Male & 60 \\
\hline Female & 22 \\
\hline Age(years) & $67.1 \pm 8.5$ \\
\hline BMI before surgery $\left(\mathrm{kg} / \mathrm{m}^{2}\right)$ & $21.8 \pm 2.1$ \\
\hline \multicolumn{2}{|l|}{ EGOG performance status } \\
\hline 0 & 78 \\
\hline 1 & 4 \\
\hline \multicolumn{2}{|l|}{ Approach } \\
\hline Open & 51 \\
\hline Laparoscopic & 31 \\
\hline \multicolumn{2}{|l|}{ Surgical procedure } \\
\hline DG & 57 \\
\hline TG & 25 \\
\hline \multicolumn{2}{|l|}{ Lymph node dissection } \\
\hline D1 & 5 \\
\hline $\mathrm{D} 1+$ & 25 \\
\hline D2 & 50 \\
\hline $\mathrm{D} 2+$ & 2 \\
\hline \multicolumn{2}{|l|}{ Reconstruction method } \\
\hline B1 & 32 \\
\hline RY & 46 \\
\hline B2 & 3 \\
\hline IP & 1 \\
\hline \multicolumn{2}{|l|}{ Combined resection } \\
\hline Yes & 24 \\
\hline No & 58 \\
\hline \multicolumn{2}{|l|}{ Pathological stage } \\
\hline I & 39 \\
\hline II & 15 \\
\hline III & 28 \\
\hline \multicolumn{2}{|l|}{ Adjuvant chemotherapy } \\
\hline Yes & 33 \\
\hline No & 49 \\
\hline
\end{tabular}

$B 1$ Billroth I, B2 Billroth II, BMI body mass index, $D G$ distal gastrectomy, ECOG Eastern Cooperative Oncology Group, IP interposition of jejunum, $R Y$ Roux-en-Y, $T G$ total gastrectomy

\section{Treatment outcome}

The median body weight before gastrectomy was $57.4 \mathrm{~kg}$ $(35.7-77.7 \mathrm{~kg})$. This declined significantly to $52.6 \mathrm{~kg}$ $(33.8-73.0 \mathrm{~kg}$ ) after 3 months postoperatively (Fig. 3a). The average rate of BWL after 3 months postoperatively compared with the preoperative body weight was $8.3 \%$ (95\% CI 7.1-9.4\%) (Fig. 3b). There was a statistically significant correlation between the rate of BWL and adherence to $\mathrm{Racol}^{\circledR} \mathrm{NF}$ therapy, with a regression coefficient of $0.427(P<0.001)$, which meant that greater adherence to Racol ${ }^{\circledR} \mathrm{NF}$ therapy could result in less BWL after gastrectomy (Fig. 4).

Next, patients were arbitrarily categorized into two groups according to their adherence to Racol ${ }^{\circledR} \mathrm{NF}$ therapy to evaluate how oral nutritional supplementation influenced the clinical outcomes, including the body composition and serum biochemistry, during the postoperative period. Fortyone patients who on average took more than $200 \mathrm{ml}$ of Racol ${ }^{\circledR}$ NF per day were classified into the high-adherence group (H group). The remaining 41 patients, who took less than $200 \mathrm{ml}$ of $\mathrm{Racol}^{\circledR} \mathrm{NF}$ per day, were classified into the low-adherence group (L group). The mean daily intake of $\mathrm{Racol}^{\circledR} \mathrm{NF}$ was $304 \mathrm{ml}(95 \%$ CI $282-326 \mathrm{ml})$ in the $\mathrm{H}$ group and $117 \mathrm{ml}(95 \% \mathrm{CI} 95-140 \mathrm{ml})$ in the $\mathrm{L}$ group. The clinicopathological features of the patients according to adherence to Racol ${ }^{\circledR} \mathrm{NF}$ therapy are given in Table 2. There were no significant differences in the clinicopathological characteristics except for sex between the two groups. The $\mathrm{H}$ group was associated with significantly more constrained BWL than the L group at 3 months postoperatively $[(6.1 \pm 4.3) \%$ vs $(10.4 \pm 5.2) \%, P<0.001]$ (Fig. 5a). Assessment by a linear mixed model revealed that the $\mathrm{H}$ group maintained the body weight from 1 to 3 months postoperatively, whereas the $\mathrm{L}$ group continued to lose weight throughout the 3 -month period $(P<0.001)$. There was a significant difference in the percentage of body fat loss between the two groups $[(18.4 \pm 18.5) \%$ for the $\mathrm{H}$ group vs (28.2 \pm 17.3$) \%$ for the L group, $P=0.015$ ] (Fig. 5b), whereas difference in the percentage of muscle mass loss was not significant at 3 months postoperatively [ $(3.7 \pm 5.0) \%$ for the $\mathrm{H}$ group vs $(5.5 \pm 5.1) \%$ for the $\mathrm{L}$ group, $P=0.192$ ] (Fig. 5c). There was no difference between the two groups according to the serum biochemistry data.

The total oral food intake was aggregated from the questionnaires. The ratio of the total number of days for which patients had a meal intake of $75 \%$ or more compared with the preoperative ingestion was similar between the two groups (39\% for the $\mathrm{H}$ group vs $36 \%$ for the $\mathrm{L}$ group), that for a meal intake from $50 \%$ to less than $75 \%$ was similar between the two groups (38\% for the $\mathrm{H}$ group vs $33 \%$ for the $\mathrm{L}$ group), and that for meal intake of less than $50 \%$ was also similar between the two groups (23\% for the $\mathrm{H}$ group vs $30 \%$ for the L group), which meant that both groups were comparable in terms of the oral food intake $(P=0.499)$. In addition, the patients were categorized into two groups stratified by the postoperative oral food intake to evaluate how that influenced the BWL and adherence to Racol ${ }^{\circledR} \mathrm{NF}$ therapy. In this analysis, 56 patients who took $50 \%$ or more of the preoperative oral food intake during more than half of the observation period were classified into the robust oral ingestion group ( $\mathrm{R}$ group), and the remaining 20 patients were classified into the unstable oral ingestion group 


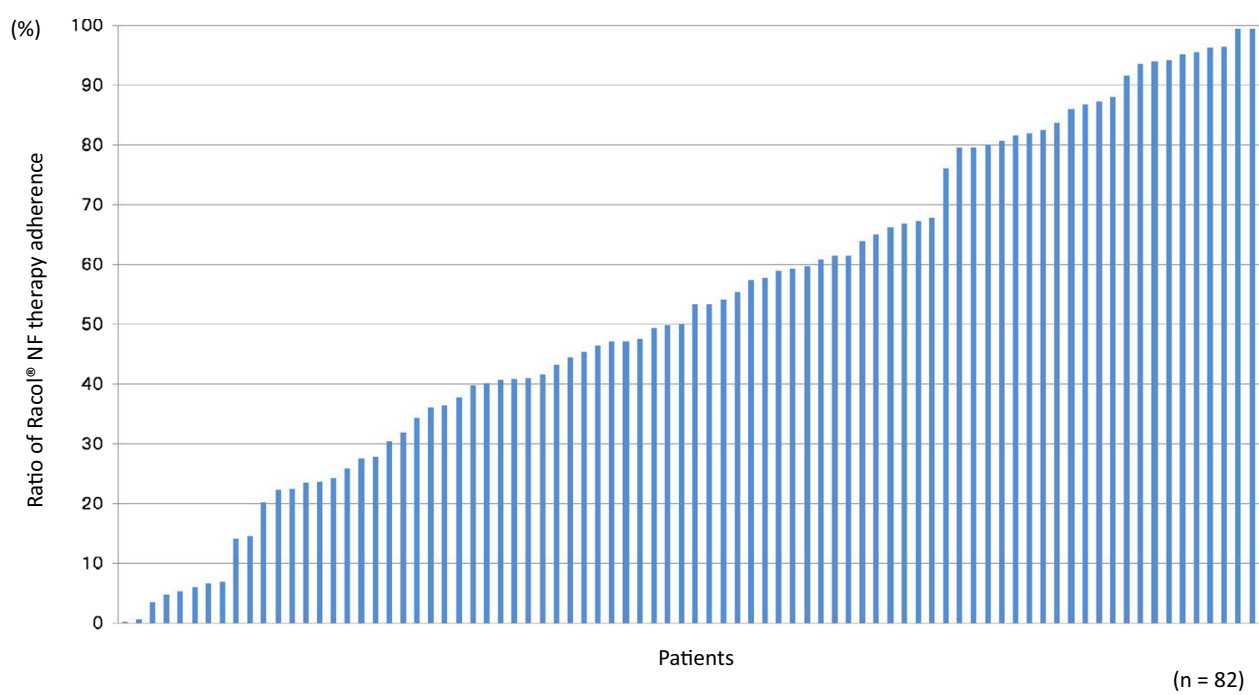

Fig. 2 Adherence to $\operatorname{Racol}^{\circledR} \mathrm{NF}$ therapy. The total intake of Racol ${ }^{\circledR}$ NF during the 3 months postoperatively was divided by the recommended amount of $\operatorname{Racol}^{\circledR} \mathrm{NF} \quad(400 \mathrm{ml} \times 83$ days $=$ $33,200 \mathrm{ml})$ to calculate the relative dose intensity of Racol ${ }^{\circledR} \mathrm{NF}$ in

(U group). Six patients who did not respond to the questionnaire were excluded. The $\mathrm{R}$ group was associated with less BWL than the U group at 3 months postoperatively, although not significantly so $[(7.3 \pm 4.5) \%$ vs $(10.3 \pm 5.8) \%, P=0.058]$. In addition, the mean daily $\mathrm{Racol}^{\circledR} \mathrm{NF}$ intake was significantly greater in the R group than in the U group [215 $\mathrm{ml}(95 \%$ CI $188-243 \mathrm{ml})$ vs $174 \mathrm{ml}(95 \%$ CI 109-239 ml), $P=0.025]$.

We also made a comparison between different surgical procedures. The difference in the degree of BWL between the $\mathrm{H}$ group and the $\mathrm{L}$ group at 3 months postoperatively was statistically significant among patients who underwent distal gastrectomy $[(4.9 \pm 4.0) \%$ vs $(9.5 \pm 4.0) \%$, $P<0.001]$, but not among those who underwent total gastrectomy $[(9.1 \pm 3.2) \%$ vs $(12.6 \pm 6.7) \%, P=0.097]$. This may reflect a detrimental effect of total gastrectomy besides the issue of sample size.

The multiple linear regression analysis has shown, however, that adherence to Racol ${ }^{\circledR} \mathrm{NF}$ therapy was the only factor that correlated with BWL ratio among all clinical characteristics, including the percentage of total oral food intake of $50 \%$ greater and the extent of gastrectomy $(P=0.007)$.

\section{Discussion}

The efficacy of nutritional support to manage postoperative malnutrition for gastric cancer patients is yet to be robustly proven, although it has become recognized that poor nourishment could trigger unfavorable treatment outcomes each patient. The maximum adherence was $99.4 \%$, whereas the minimum was $0.2 \%$. The average daily $\operatorname{Racol}^{\circledR} \mathrm{NF}$ intake was $211 \mathrm{ml}$ (95\% CI 186-236 ml)

not only among postgastrectomy patients but also in those with virtually any kind of debilitating disease. Patients with advanced gastric cancer face a major challenge of receiving adjuvant chemotherapy and tolerating subsequent adverse events during the time when their food intake is unstable. Oral nutritional supplementation as advocated in ESPEN guidelines can be an appropriate concept from the viewpoint of its synonym "sip feeds" for those with alteration of the upper gastrointestinal tract. We attempted to deliver an oral nutritional supplementation program to patients after gastrectomy using $\mathrm{Racol}^{\circledR} \mathrm{NF}$ for 3 months postoperatively and found that patients who tolerated $50 \%$ or more of the initially planned dose of Racol ${ }^{\circledR} \mathrm{NF}$ benefited from significantly reduced BWL compared with those who failed to do so. The study was a failure in that the initial planned dose of $400 \mathrm{ml}$ to load $400 \mathrm{kcal}$ in addition to the regular meal was intolerable for most of the patients, but the study provided a new finding that nutritional support aiming for that dose did seem meaningful in the study population. Rather unexpectedly, the extent of gastrectomy had little impact on the adherence to Racol ${ }^{\circledR} \mathrm{NF}$ therapy. Thus, Racol ${ }^{\circledR} \mathrm{NF}$ at the proposed dose could be recommended regardless of the type of surgery for a future trial to explore oral nutritional supplementation after gastrectomy, especially for patients who are to undergo postoperative adjuvant chemotherapy.

The present study simultaneously shed light on the difficulty to boost oral intake followed gastrectomy. Again, the average adherence to Racol ${ }^{\circledR} \mathrm{NF}$ intake in addition to regular food was nearly half of what was expected in advance. Patients after gastrectomy originally experience several 
Table 2 Patient characteristics classified by adherence to Racol ${ }^{\circledR}$ NF therapy

\begin{tabular}{|c|c|c|c|}
\hline Variable & Low-adherence group $(n=41)$ & High-adherence group $(n=41)$ & $P^{\mathrm{a}}$ \\
\hline \multicolumn{4}{|l|}{ Sex } \\
\hline Male & 25 & 35 & \multirow[t]{2}{*}{0.042} \\
\hline Female & 16 & 6 & \\
\hline Age (years) & $66.6 \pm 8.8$ & $67.5 \pm 8.4$ & 0.335 \\
\hline BMI before surgery $\left(\mathrm{kg} / \mathrm{m}^{2}\right)$ & $22.2 \pm 1.7$ & $21.4 \pm 2.4$ & 0.131 \\
\hline \multicolumn{4}{|l|}{ ECOG Performance status } \\
\hline 0 & 38 & 40 & \multirow[t]{2}{*}{0.305} \\
\hline 1 & 3 & 1 & \\
\hline \multicolumn{4}{|l|}{ Approach } \\
\hline Open & 26 & 25 & \multirow[t]{2}{*}{0.820} \\
\hline Laparoscopic & 15 & 16 & \\
\hline \multicolumn{4}{|l|}{ Surgical procedure } \\
\hline DG & 28 & 29 & \multirow[t]{2}{*}{0.810} \\
\hline TG & 13 & 12 & \\
\hline \multicolumn{4}{|l|}{ Lymph node dissection } \\
\hline D1 & 2 & 3 & \multirow[t]{4}{*}{0.350} \\
\hline D1+ & 15 & 10 & \\
\hline D2 & 24 & 26 & \\
\hline D2+ & 0 & 2 & \\
\hline \multicolumn{4}{|l|}{ Reconstruction method } \\
\hline B1 & 15 & 17 & \multirow[t]{4}{*}{0.672} \\
\hline RY & 24 & 22 & \\
\hline $\mathrm{B} 2$ & 1 & 2 & \\
\hline IP & 1 & 0 & \\
\hline \multicolumn{4}{|l|}{ Combined resection } \\
\hline Yes & 26 & 32 & \multirow[t]{2}{*}{0.225} \\
\hline No & 15 & 9 & \\
\hline \multicolumn{4}{|l|}{ Pathological stage } \\
\hline I & 20 & 19 & \multirow[t]{3}{*}{0.971} \\
\hline II & 7 & 8 & \\
\hline III & 14 & 14 & \\
\hline \multicolumn{4}{|l|}{ Adjuvant chemotherapy } \\
\hline Yes & 23 & 27 & \multirow[t]{2}{*}{0.371} \\
\hline No & 19 & 14 & \\
\hline
\end{tabular}

$B 1$ Billroth I, B2 Billroth II, BMI body mass index, $D G$ distal gastrectomy, ECOG Eastern Cooperative Oncology Group, $I P$ interposition of jejunum, $R Y$ Roux-en-Y, $T G$ total gastrectomy

a The chi-square test, Fisher's exact test, and the Mann-Whitney $U$ test were used to assess differences between the two groups symptoms caused by loss of part or all of the stomach. Intensive patient education by a nutrition support team to increase of the number of feeding opportunities to cover the small amount tolerated per occasion as well as for patients to adhere to an adequate oral nutritional supplementation program would be useful to reduce the BWL [14].

In this series, patients in the $\mathrm{H}$ group retained significantly greater fat mass compared with patients in the $\mathrm{L}$ group. The degree of muscle mass depletion was not statistically different between the two groups, although the $\mathrm{L}$ group did continue to lose muscle mass during the
3 months postoperatively, whereas the $\mathrm{H}$ group demonstrated slight recovery of the muscle mass loss after 2 months postoperatively. Thus, reduction in BWL is the consequence of body fat preservation owing to sufficient oral nutrition. Recently, sarcopenia, which is characterized by a progressive and generalized decrease in the amount and strength of skeletal muscle, was shown to be associated with poor outcomes in several malignancies $[15,16]$. It has also been reported that sarcopenia is a significant risk factor for postoperative complications and survival following gastrectomy [17, 18]. Since the lean body mass 
Fig. 3 Body weight loss during the 3 months postoperatively. a Body weight change before surgery and 3 months after surgery: It was statistically significant by the Wilcoxon signed-rank test that the median body weight $57.4 \mathrm{~kg}$ before gastrectomy declined to $52.6 \mathrm{~kg}$ after 3 months postoperatively. b Body weight loss ratio: body weight loss after 3 months postoperatively was divided by the preoperative body weight, which gave the average percentage body weight loss, $8.3 \%$

Fig. 4 Relation between body weight loss and adherence to Racol ${ }^{\circledR}$ NF therapy. There was a statistically significant correlation between the body weight loss ratio and adherence to Racol ${ }^{\circledR} \mathrm{NF}$ therapy by correlation analysis. Therefore, greater adherence to Racol ${ }^{\circledR} \mathrm{NF}$ therapy could result in less body weight loss after gastrectomy a

(kg)

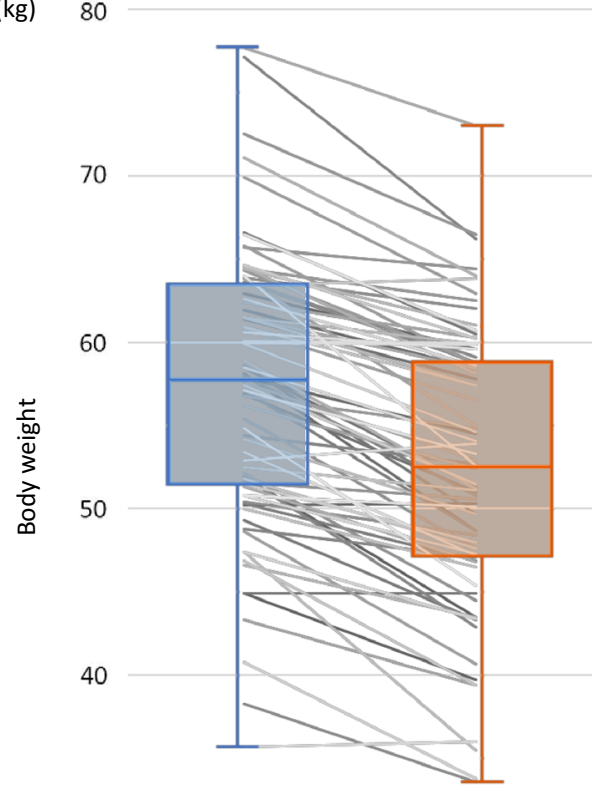

30

Before surgery 3 months after surgery

$\begin{array}{lll}\text { Median } & 57.4 \mathrm{~kg} & 52.6 \mathrm{~kg} \\ \text { Min. } & 35.7 \mathrm{~kg} & 33.8 \mathrm{~kg} \\ \text { Max. } & 77.7 \mathrm{~kg} & 73.0 \mathrm{~kg}\end{array}$

b

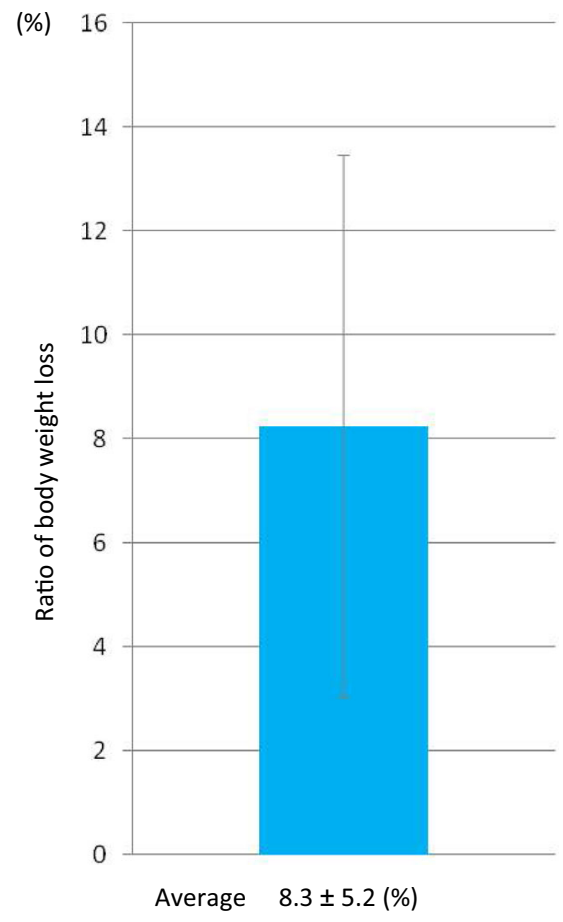

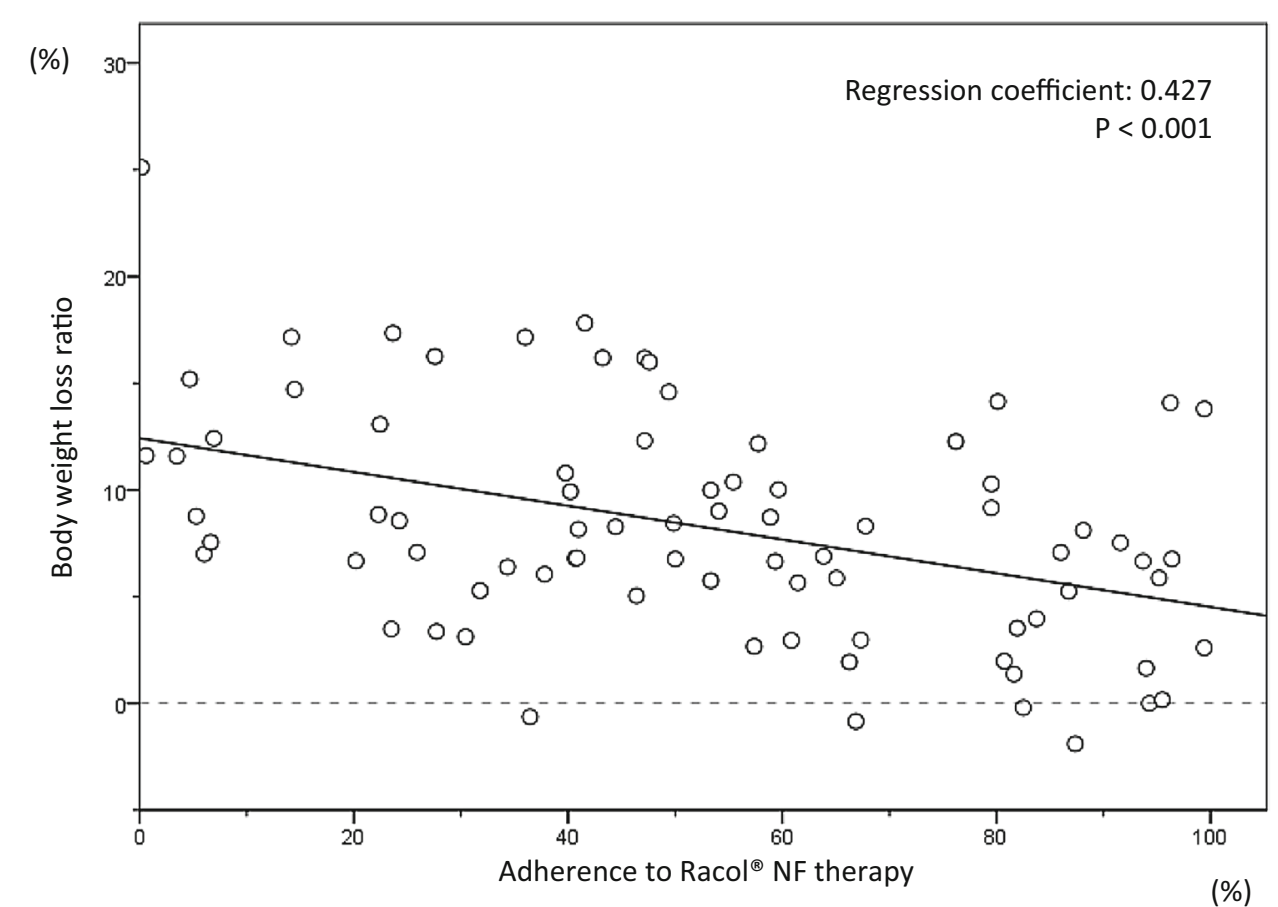

(\%)

during the early postoperative phase has been considered a surrogate of adherence to postoperative adjuvant chemotherapy [19], and has often been reported to be associated with quality of life [20], some considerations may be required not only to minimize the BWL but also to preserve the lean body mass. Our data suggest that sufficient intake of $\mathrm{Racol}^{\circledR} \mathrm{NF}$ may contribute in this aspect as well. 
Fig. 5 Change of body composition between the two groups, with a score of $100 \%$ representing the preoperative body composition. a Body weight change. It was statistically significant that the high-adherence group (H group) maintained the percentage of body weight loss $(B W L)$ from 1 month to 3 months postoperatively by the linear mixed model and that high adherence exerted a more constraining influence on body weight loss than did low adherence at 3 months postoperatively by the Mann-Whitney $U$ test. b Body fat change. The patients in the $\mathrm{H}$ group retained significantly greater fat mass compared with patients in the low-adherence group ( $L$ group) at 3 months postoperatively by the MannWhitney $U$ test. c Muscle mass change. The degree of muscle mass depletion was not statistically different between the two groups. POM postoperative month

\section{a}

\section{Body weight change}

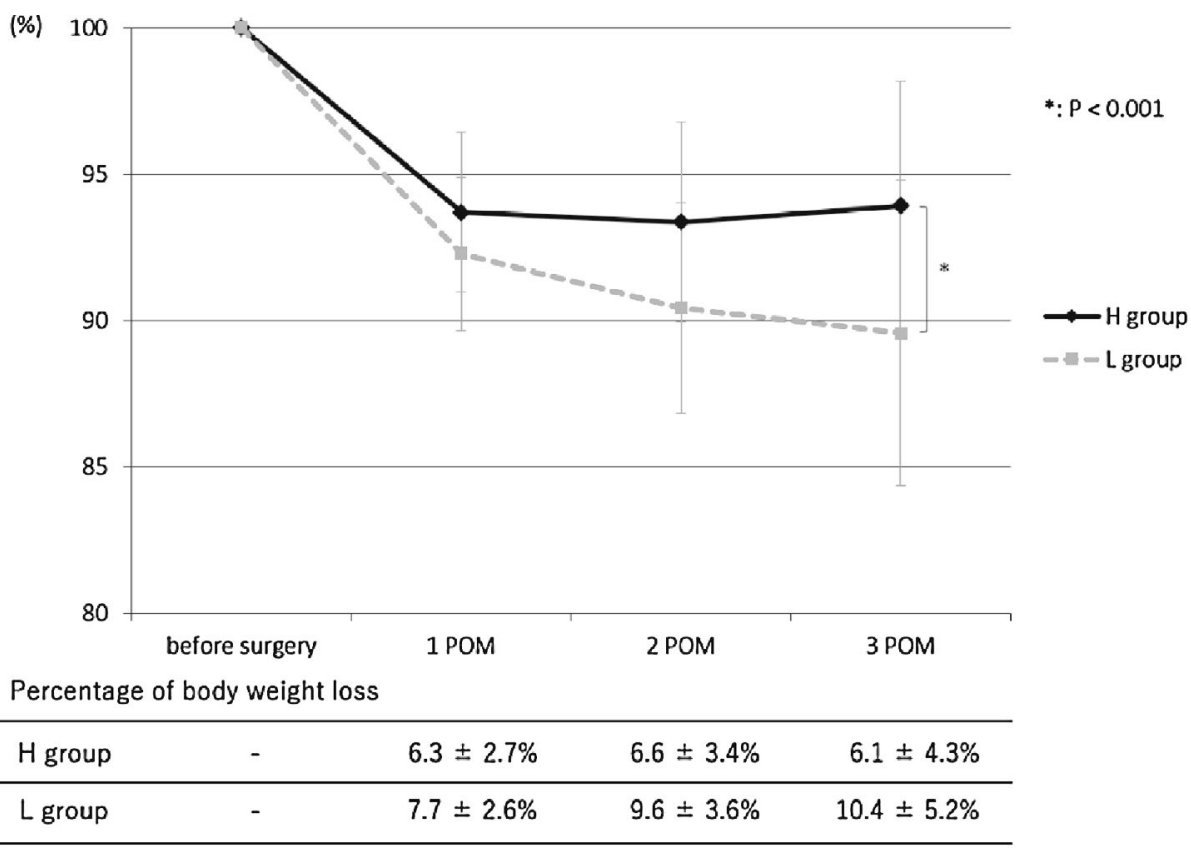

b

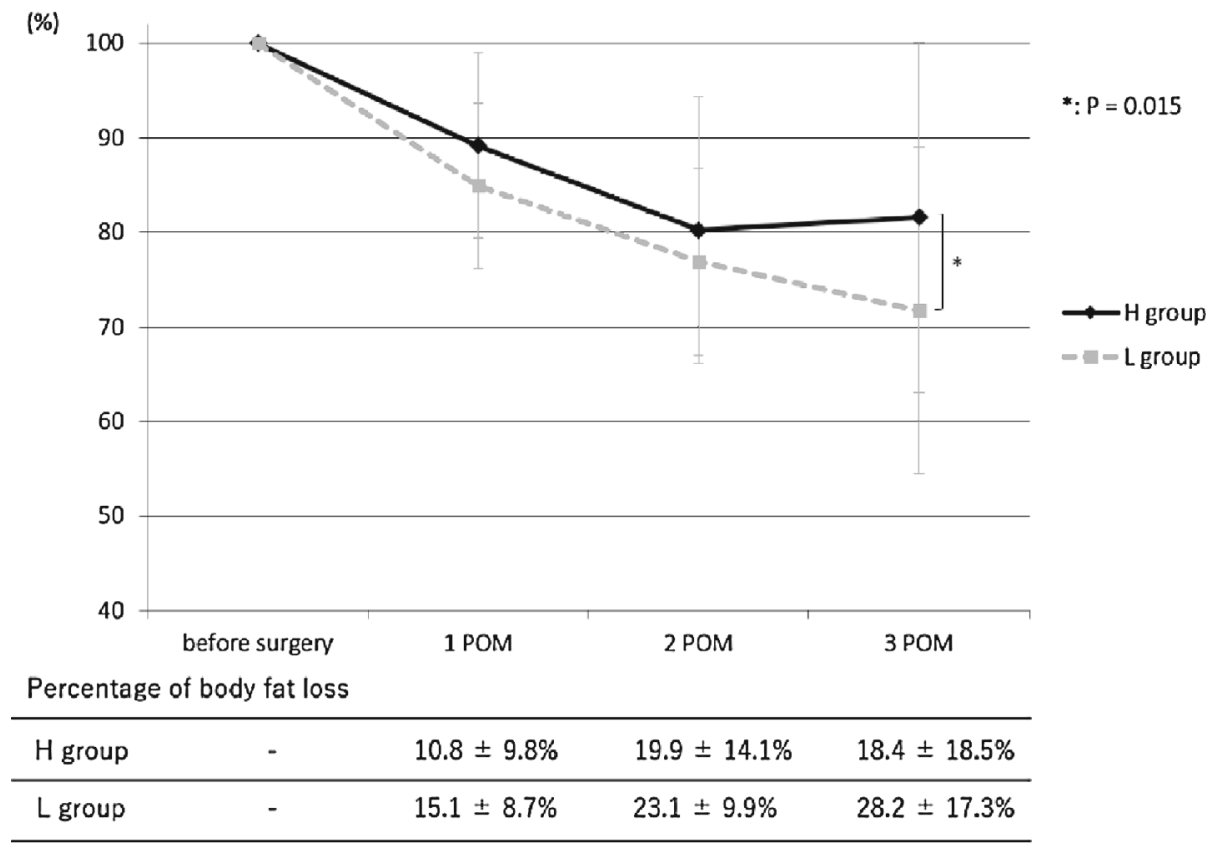

Since our effort to adopt oral nutritional supplementation only postoperatively along with the duration of 3 months does not seem sufficient to avoid depletion of the muscle mass, a program incorporating intensive preoperative nutritional support and perhaps using other nutrients could be considered and explored. Indeed, nutritional formulae have not been standardized after gastrectomy, although several kinds of nutritional supplements have been introduced. In the current study, we used Racol ${ }^{\circledR} \mathrm{NF}$, taking advantage of some favorable features from a nutritional perspective. It consists of the three major nutrients, with $62 \%$ carbohydrate, $20 \%$ fat, and $18 \%$ protein, in what 
Fig. 5 continued

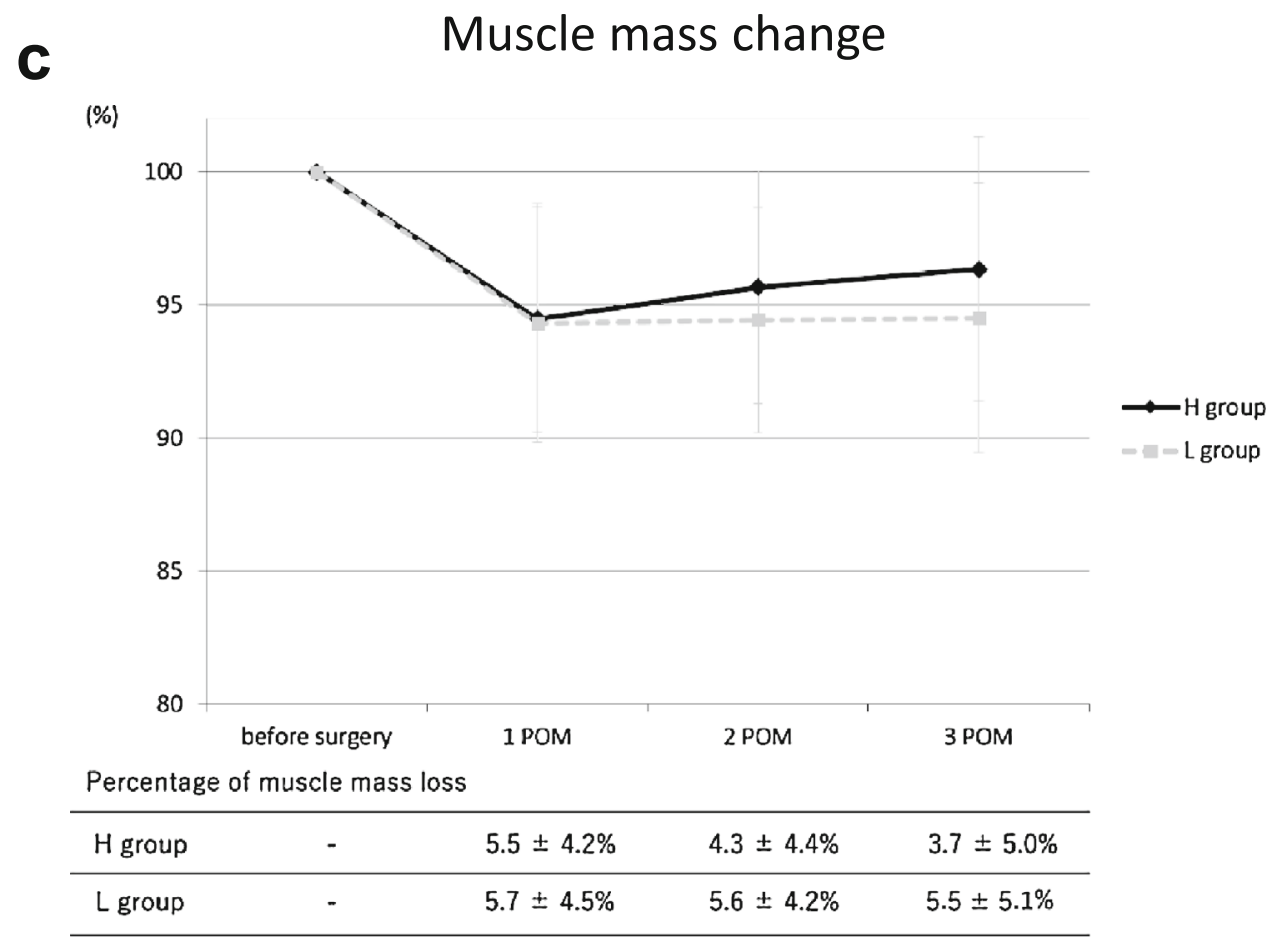

is thought to be the optimal equilibrium. In addition, the proportion of omega-3 and omega- 6 essential fatty acids in $\mathrm{Racol}^{\circledR} \mathrm{NF}$ is adjusted to be $1: 3$, which is considered within the desirable range for reducing the risk of chronic diseases and some malignancies [21]. On the other hand, an eicosapentaenoic acid (EPA)-enriched diet reportedly preserved lean body mass after esophageal cancer surgery, suggesting that EPA has beneficial effects on body composition in patients who undergo major surgery [22]. In the human body, $\alpha$-linolenic acid is metabolized to eicosatetraenoic acid by $\Delta^{6}$ desaturase, and subsequently eicosatetraenoic acid is metabolized to EPA by $\Delta^{5}$ desaturase. Finally, EPA is metabolized to docosahexaenoic acid. EPA-containing nutritional supplements will be useful as ONS for patients after gastrectomy from that viewpoint. Elental ${ }^{\circledR}$ (EA Pharma, Japan), with a low fat content and that contains amino acids, which do not require digestion as a source of nitrogen, was reported to be effective in reducing postoperative weight loss in gastric cancer patients undergoing gastrectomy [23]. Although oral nutritional supplementation with $\mathrm{Racol}^{\circledR} \mathrm{NF}$ has shown some promise in the present study, comparative trials are still required to find the most appropriate nutritional agent or a combination of agents to manage postgastrectomy status with organic and functional alterations in the digestive system.

Our study has several limitations. All patients were Japanese, and both safety and efficacy data would be applicable only in the Far East [24]. The study was not a randomized trial, comprising one arm. Patients freely consumed both Racol ${ }^{\circledR} \mathrm{NF}$ and ordinary food. Although the data for $\mathrm{Racol}^{\circledR} \mathrm{NF}$ intake were accumulated with utmost care, the data for oral ingestion were not sufficiently precise to calculate the actual dietary caloric intake. Although the multiple linear regression analysis was conducted to adjust the data for the influence of oral food intake, it remains difficult in this study to nullify the possibility that it was the eating capacity of the patients in the $\mathrm{H}$ group rather than the amount of $\mathrm{Racol}^{\circledR} \mathrm{NF}$ tolerated that ultimately influenced the outcome. The sample size was too small and the observation period too short to see whether oral nutritional supplementation affected longterm outcomes such as overall survival and progressionfree survival. Further clinical trials that could overcome these issues are desired to clarify the optimal nutritional intervention for those who need gastrectomy in the future, and the current study could be help to design such trials.

In conclusion, oral nutritional supplementation with $\mathrm{Racol}^{\circledR} \mathrm{NF}$ led to a significant reduction in body weight loss for gastrectomized patients who tolerated more than $200 \mathrm{ml}$ of the nutrient per day compared with those who could not tolerate this amount.

\section{Compliance with ethical standards}

Funding This research did not receive any specific grant from funding agencies in the public, commercial, or not-for-profit sectors.

Conflict of interest Daisuke Kobayashi has received personal fees from Taiho Pharmaceutical, personal fees from Chugai 
Phamaceutical, personal fees from Yakult Honsha, personal fees from AJINOMOTO Pharmaceuticals, outside the submitted work. Masahiko Ando received a grant from Kyowa Hakko Kirin Co., Ltd., outside the submitted work. Yasuhiro Kodera has received grants and personal fees from Taiho Pharmaceutical, grants and personal fees from Chugai Phamaceutical, grants and personal fees from Sanofi, grants and personal fees from Merck Serono, grants and personal fees from Yakult Honsha, grants and personal fees from Daiichi Sankyo, grants and personal fees from Otsuka Pharmaceutical Factory, grants and personal fees from Takeda Pharmaceutical, grants and personal fees from Johnson \& Johnson, grants and personal fees from Asahi Kasei Pharma, grants and personal fees from Eli Lilly Japan, grants and personal fees from Pfizer Japan, grants and personal fees from AJINOMOTO Pharmaceuticals, grants and personal fees from ONO Pharmaceutical, grants and personal fees from Kaken Pharmaceutical, grants from Covidien Japan, grants from Shionogi, grants from Bristol-Myers Squib, grants from Japan Blood Products Organization, grants from Torii Pharmaceutical, grants from Mitsubishi Tanabe Pharma, grants from AbbVie GK, grants from Otsuka Pharmaceutical, grants from Yoshindo, grants from Eizai, grants from Abbott Japan, grants from CSL Behring, grants from Teijin Pharma, grants from Tsumura, grants from Nippon Kayaku, grants from Miyarisan Pharmaceutical, grants from Novartis Pharmaceuticals Japan, grants from KCI, grants from Toyama Chemical, grants from Maruho, personal fees from Hogy Medical, personal fees from MSD, outside the submitted work.

Human rights statement and informed consent All procedures followed were in accordance with the ethical standards of the responsible committee on human experimentation (institutional and national) and with the Helsinki Declaration of 1964 and later versions. Informed consent or substitute for it was obtained from all patients for their being included in the study.

\section{References}

1. International Agency for Research on Cancer. GLOBOCAN 2012. http://globocan.iarc.fr (2016). Accessed 1 Jul 2016.

2. Japanese Gastric Cancer Association. Japanese gastric cancer treatment guidelines 2014 (ver. 4). Gastric Cancer. 2016. doi:10. 1007/s10120-016-0622-4.

3. Bae JM, Park JW, Yang HK, Kim JP. Nutritional status of gastric cancer patients after total gastrectomy. World J Surg. 1998;22:254-60.

4. Abdiev S, Kodera Y, Fujiwara M, Koike M, Nakayama G, Ohashi $\mathrm{N}$, et al. Nutritional recovery after open and laparoscopic gastrectomies. Gastric Cancer. 2011;14:144-9.

5. Choi WJ, Kim J. Nutritional care of gastric cancer patients with clinical outcomes and complications: a review. Clin Nutr Res. 2016;5:65-78.

6. Yu W, Seo BY, Chung HY. Postoperative body-weight loss and survival after curative resection for gastric cancer. Br J Surg. 2002;89:467-70.

7. Tokunaga M, Tanizawa Y, Bando E, Kawamura T, Terashima M. Poor survival rate in patients with postoperative intra-abdominal infectious complications following curative gastrectomy for gastric cancer. Ann Surg Oncol. 2013;20:1575-83.

8. Jiang N, Deng JY, Ding XW, Zhang L, Liu HG, Liang YX, et al. Effect of complication grade on survival following curative gastrectomy for carcinoma. World J Gastroenterol. 2014;20:8244-52.
9. Sakuramoto S, Sasako M, Yamaguchi T, Kinoshita T, Fujii M, Nashimoto A, et al. Adjuvant chemotherapy for gastric cancer with S-1, an oral fluoropyrimidine. N Engl J Med. 2007;357: 1810-20.

10. Aoyama T, Yoshikawa T, Shirai J, Hayashi T, Yamada T, Tsuchida $\mathrm{K}$, et al. Body weight loss after surgery is an independent risk factor for continuation of S-1 adjuvant chemotherapy for gastric cancer. Ann Surg Oncol. 2013;20:2000-6.

11. Cunningham D, Allum WH, Stenning SP, Thompson JN, Van de Velde CJ, Nicolson M, et al. Perioperative chemotherapy versus surgery alone for resectable gastroesophageal cancer. N Engl J Med. 2006;355:11-20.

12. Lochs H, Allison SP, Meier R, Pirlich M, Kondrup J, Schneider $\mathrm{S}$, et al. Introductory to the ESPEN guidelines on enteral nutrition: terminology, definitions and general topics. Clin Nutr. 2006;25:180-6.

13. Weimann A, Braga M, Harsanyi L, Laviano A, Ljungqvist O, Soeters $\mathrm{P}$; DGEM, et al. ESPEN guidelines on enteral nutrition: surgery including organ transplantation. Clin Nutr. 2006;25(2):224-44.

14. Lee HO, Han SR, Choi SI, Lee JJ, Kim SH, Ahn HS, et al. Effects of intensive nutrition education on nutritional status and quality of life among postgastrectomy patients. Ann Surg Treat Res. 2016;90:79-88.

15. Antoun S, Lanoy E, Iacovelli R, Albiges-Sauvin L, Loriot Y, Merad-Taoufik M, et al. Skeletal muscle density predicts prognosis in patients with metastatic renal cell carcinoma treated with targeted therapies. Cancer. 2013;119:3377-84.

16. Delmonico MJ, Harris TB, Lee JS, Visser M, Nevitt M, Kritchevsky SB, et al. Health, aging and body composition study. alternative definitions of sarcopenia, lower extremity performance, and functional impairment with aging in older men and women. J Am Geriatr Soc. 2007;55:769-74.

17. Sato T, Aoyama T, Hayashi T, Segami K, Kawabe T, Fujikawa H, et al. Impact of preoperative hand grip strength on morbidity following gastric cancer surgery. Gastric Cancer. 2016;19:1008-15.

18. Zhuang CL, Huang DD, Pang WY, Zhou CJ, Wang SL, Lou N, et al. Sarcopenia is an independent predictor of severe postoperative complications and long-term survival after radical gastrectomy for gastric cancer: analysis from a large-scale cohort. Medicine (Baltimore). 2016;95:e3164.

19. Aoyama T, Kawabe T, Fujikawa H, Hayashi T, Yamada T, Tsuchida $\mathrm{K}$, et al. Loss of lean body mass as an independent risk factor for continuation of S-1 adjuvant chemotherapy for gastric cancer. Ann Surg Oncol. 2015;22:2560-6.

20. Gullett NP, Mazurak VC, Hebbar G, Ziegler TR. Nutritional interventions for cancer-induced cachexia. Curr Probl Cancer. 2011;35:58-90.

21. Simopoulos AP. The importance of the ratio of omega-6/omega-3 essential fatty acids. Biomed Pharmacother. 2002;56:365-79.

22. Ryan AM, Reynolds JV, Healy L, Byrne M, Moore J, Brannelly $\mathrm{N}$, et al. Enteral nutrition enriched with eicosapentaenoic acid (EPA) preserves lean body mass following esophageal cancer surgery: results of a double-blinded randomized controlled trial. Ann Surg. 2009;249:355-63.

23. Imamura $H$, Nishikawa $K$, Kishi $K$, Inoue $K$, Matsuyama J, Akamaru Y, et al. Effects of an oral elemental nutritional supplement on post-gastrectomy body weight loss in gastric cancer patients: a randomized controlled clinical trial. Ann Surg Oncol. 2016;23:2928-35.

24. Kim J, Sun CL, Mailey B, Prendergast C, Artinyan A, Bhatia S, et al. Race and ethnicity correlate with survival in patients with gastric adenocarcinoma. Ann Oncol. 2010;21:152-60. 